\title{
Kaynamama sınıflaması
}

\section{Classification of nonunions}

\author{
Kubilay Beng ${ }^{1}$, Ahmet Aybar ${ }^{2}$ \\ ${ }^{1}$ Metin Sabancı Baltalimanı Kemik Hastalıkları Eğitim Araştırma Hastanesi, Ortopedi ve Travmatoloji Kliniği, İstanbul \\ ${ }^{2}$ Gaziosmanpaşa Taksim Eğitim ve Araştırma Hastanesi, Ortopedi ve Travmatoloji Kliniği, İstanbul
}

Kaynamamalar kabaca septik ve aseptik olarak ayrılabilir. Septik kaynamamalarda altta yatan bir enfeksiyon varken, aseptik kaynamamalarda enfeksiyon yoktur. Kaynamamış kırıklar, fragmanların uçlarındaki yaşam belirtisine göre de ikiye ayrılmaktadır. illki biyolojik olarak aktif ve vasküler olanlar (hipertrofik); ikincisi ise biyolojik olarak aktif olmayan, avasküler olanlardır (atrofik).

Anahtar sözcülkler: sınıflama; kırık; kaynamama; biyolojik potansiyel
Nonunions can be roughly classified as septic and aseptic. There is an underlying infection in the septic nonunions, and no infection in the aseptic nonunions. Nonunions are also divided into two groups according to the capability of biologic reaction on the ends of the fragments. The first one is biologically active and vascular (hypertrophic); the second is biologically inactive and avascular (atrophic).

Key words: classification; fracture; nonunion; biology

1. "Fil ayağı” kaynamama (Şekil $2 \mathrm{a}$ ve Şekil 3): Hipertrofik ve kallustan zengindir. Yetersiz tespit ve immobilizasyon ve redüksiyon sonrası erken hareket verme sonrasında görülür (Şekil 3).

2. "At ayă̆ı" kaynamama (Şekil 2b): Fil ayağı kaynamamaya göre daha az kallus vardır. Genellikle plak-vida ile yapılmış kısmen stabil olan tespitler sonrası oluşur. Kırık parçalarının ucunda az miktarda kallus ve skleroz gözlenir.

3. Oligotrofik Kaynamama (Şekil 2c): Kırık uçları vaskülerdir, ancak kallus yoktur. Kırı̆ın major deplasmanı, kırık parçaların distraksiyonu ya da kırık parçaların tam redüksiyonu yapılmadan tespiti sonrasında gözlenir (Şekil 4).

\section{ATROFIK (AVASKÜLER) KAYNAMAMALAR}

Biyolojik olarak reaksiyonun olmadığı ve kırık iyileşmesinin erken aşamaları üzerine etki eden olumsuz faktörler sonucu oluşan kaynamamalardır (Şekil 5 ve Şekil 6). ${ }^{[3]}$ Stronium 85 ile yapılan çalışmalarda, kırık

- İletişim adresi: Dr. Kubilay Beng, SBU MS Baltalimanı Eğitim ve Araştırma Hastanesi, Rumelihisarı Cad. No: 62, Sarıyer, İstanbul Tel: 0532 - 6811781 e-posta: kubilaybeng@yahoo.com

- Geliș tarihi: 1 Kasım $2017 \quad$ Kabul tarihi: 1 Kasım 2017 


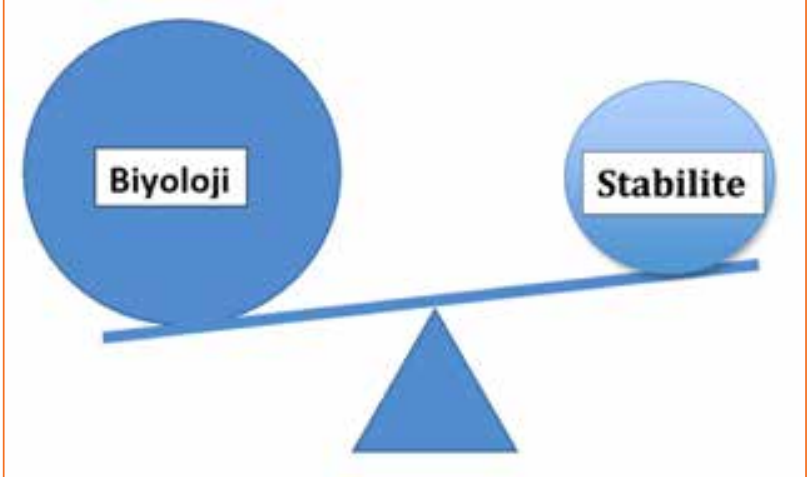

Şekil 1. Hipertrofik (vasküler) kaynamama.
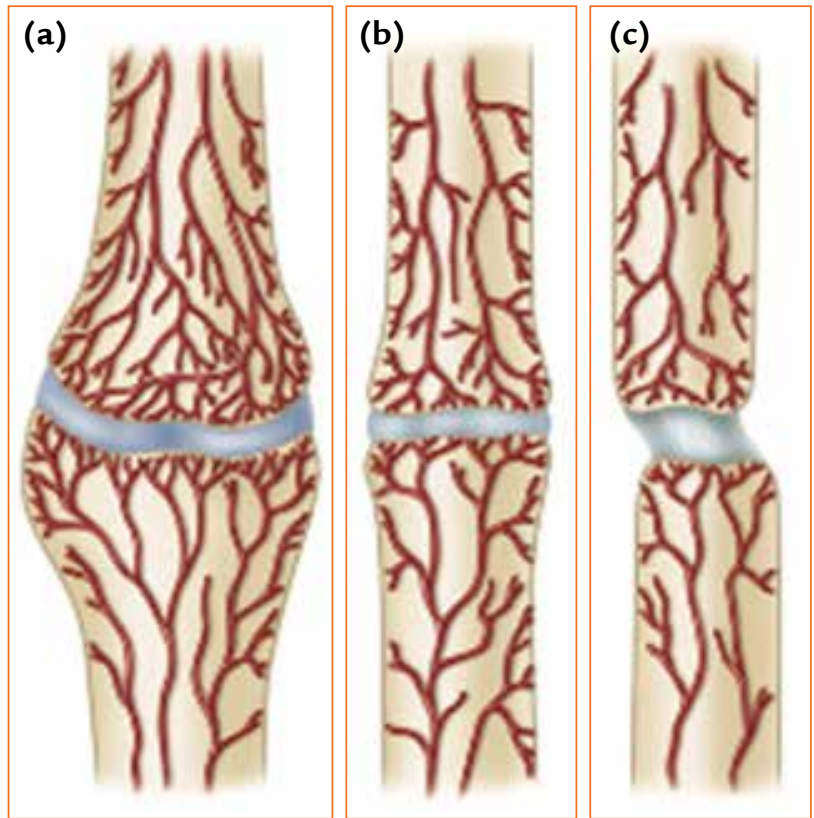

Şekil 2. a-c. Hipertrofik (vasküler) kaynamamalar: Fil ayağı kaynamama (a). At ayağı kaynamama (b). Oligotrofik kaynamama (c).

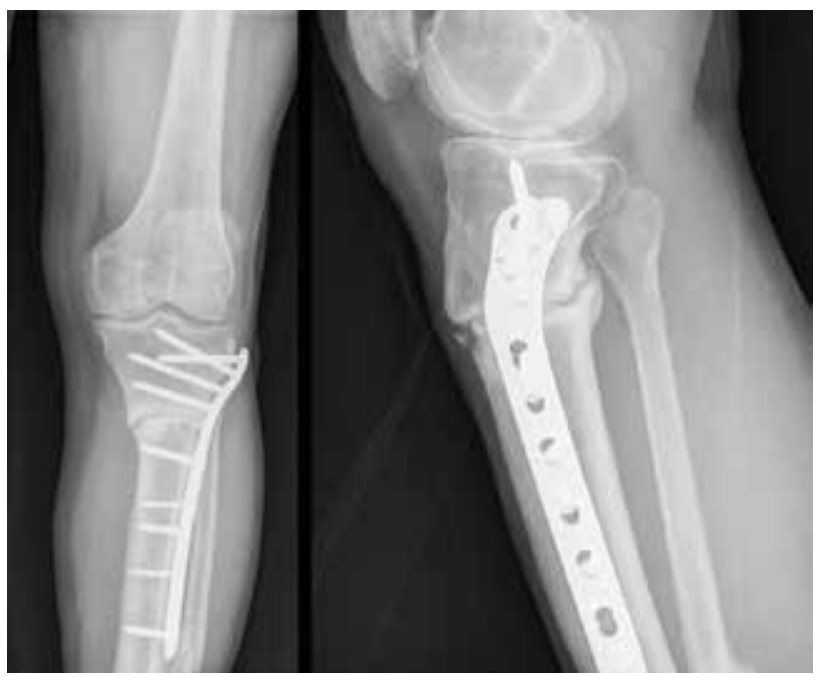

Şekil 3. Hipertrofik (vasküler) kaynamama ("fil ayağı” kaynamama).

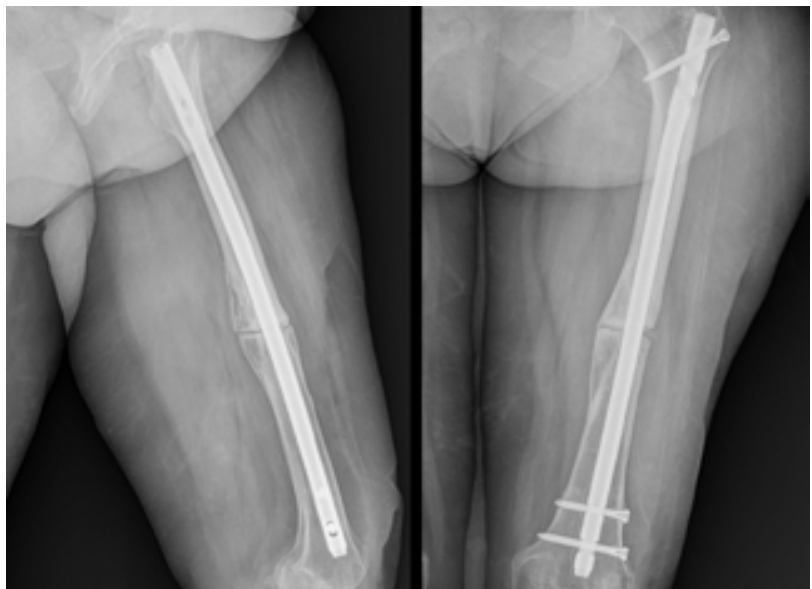

Şekil 4. Hipertrofik (vasküler) kaynamama (oligotrofik kaynamama).

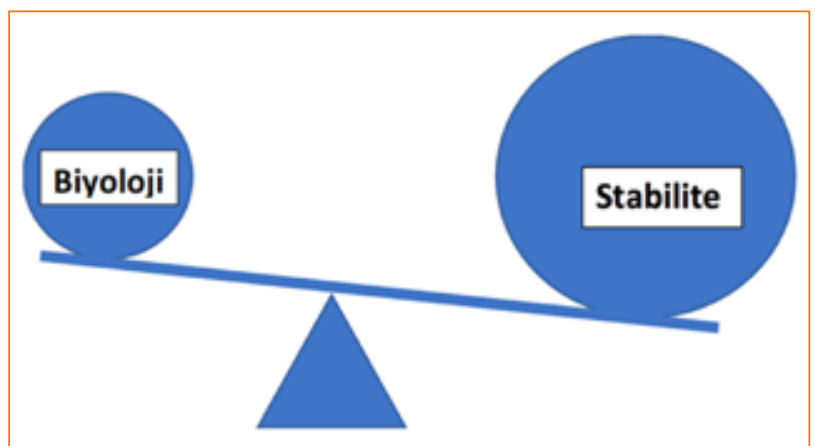

Şekil 5. Atrofik (avasküler) kaynamama.

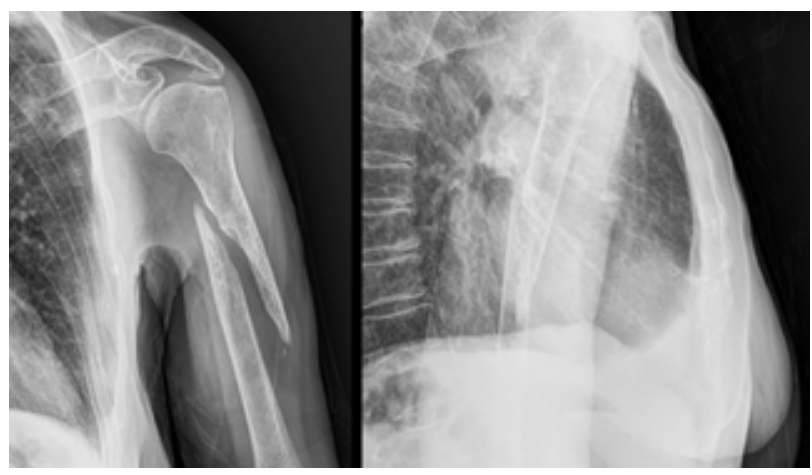

Şekil 6. Atrofik (avasküler) kaynamama.

uçlarında kan dolaşımının zayıf olduğu gösterilmiştir. Dört alt tipi vardır:

1. Torsiyon-kama tipi kaynamama (Şekil 7a): Bunlar, ortadaki parçada kan akımının azalması veya olmaması ile karakterizedir. Ortadaki parça, bir ana parçayı iyileştirirken diğerini iyileştirmez. Tipik olarak plak-vida ile tespit edilmiş tibia kırıklarında gözlenir. ${ }^{[1]}$ 

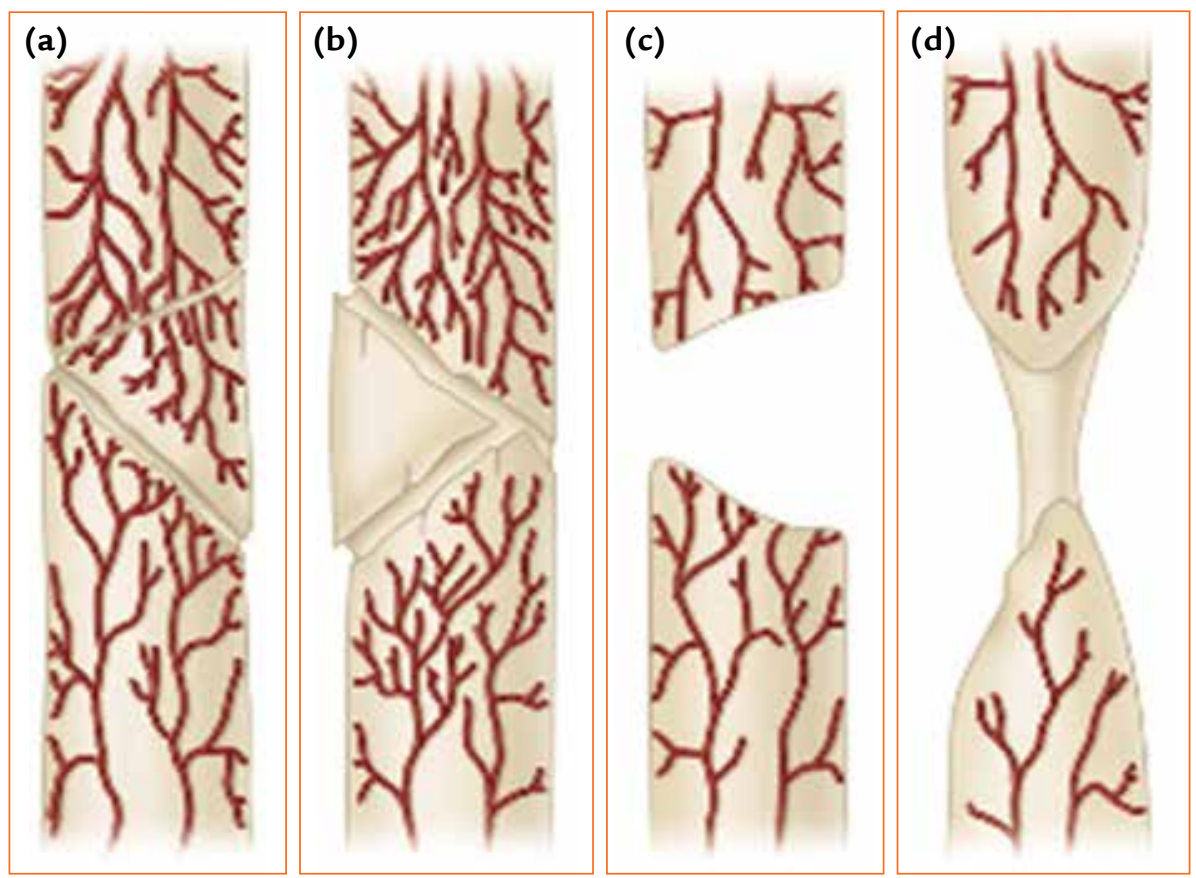

Şekil 7. a-d. Atrofik (avasküler) kaynamamalar: Torsiyon-kama tipi kaynamama (a). Torsiyon-kama tipi kaynamama (b). Torsiyon-kama tipi kaynamama (c). Torsiyon-kama tipi kaynamama (d).

2. Parçalanmış kaynamama (Şekil 7b): Nekrotik parça sayısı birden fazladır. Radyografide hiç kaynama gözlenmez. Tipik olarak, konulmuş plağın kırılması sonucu gözlenir.

3. Defektli kaynamama (Şekil 7c): Açık kırık ya da enfeksiyon sonrasında kemik parça kaybı söz konusudur. Başlangıçta kırık uçları canlıdır, ancak kemik kaybının büyüklügü kırık iyileşmesi için gereken mesafenin üzerindedir. Zamanla bu uçlar da canlılıklarını yitirir.

4. Atrofik kaynamama (Şekil 7d): Genellikle ortadaki fragmanın kaybolup, yerine osteojenik potansiyeli olmayan skar dokusun yer aldığı durumdur. Kırık uçlarının uzun süre içinde kısmen inceldiği, ekstremitede kullanılmamaya bağlı kas atrofileri ve osteoporozun geliştiği genel bir tablodur.

Paley ve ark. tibiadaki kaynamamış kırıklar için ayrı bir sınıflama geliştirdiler (Şekil 8). ${ }^{[4]}$ Buna göre;

1. Tip A Kaynamama: $1 \mathrm{~cm}$ 'den az kemik kaybı vardır.

a. Tip A1: Hareketli deformite

b. Tip A2: Fikse deformite

i. Tip A2-1: Deformitesi olmayan sert kaynamama

ii. Tip A2-2: Fikse deformitesi olan sert kaynamama

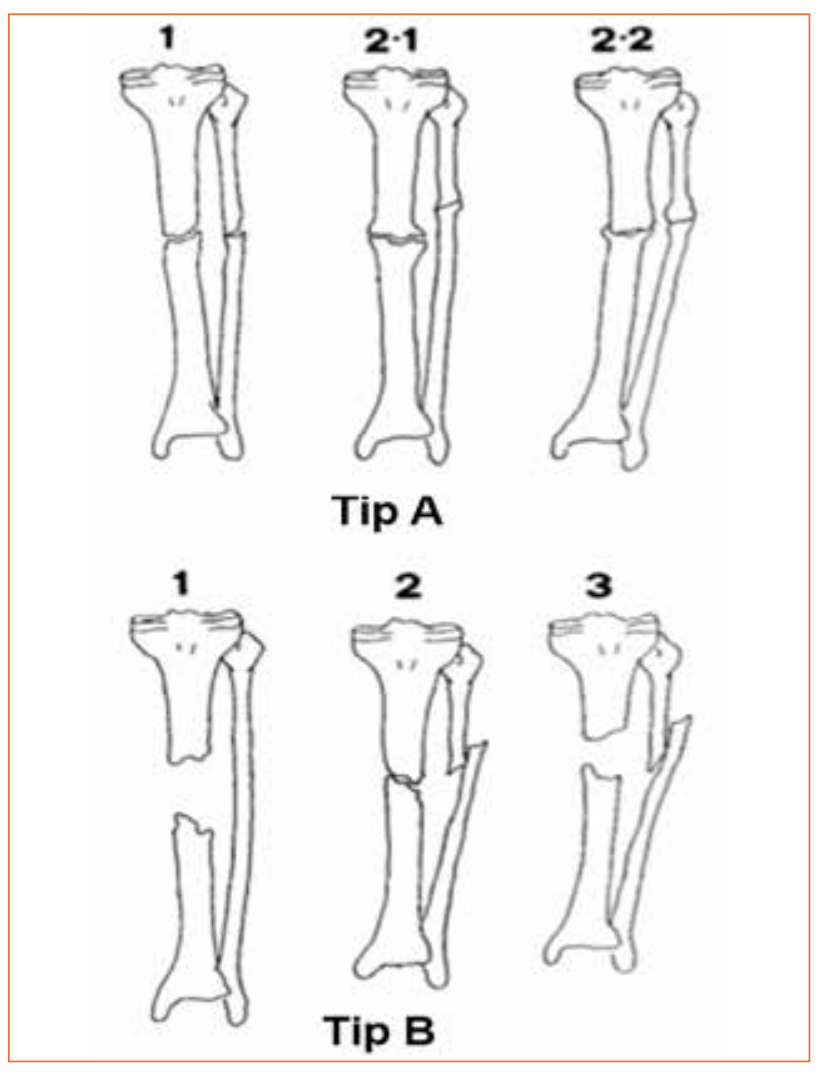

Şekil 8. Paley ve ark. tarafından tanımlanan kaynamama sınıflaması. 
2. Tip B Kaynamama: $1 \mathrm{~cm}$ 'den fazla keymik kaybı vardır.

a. Tip B1: Kemik defekti olan kaynamama

b. Tip B2: Kemik uzunluk kaybı olan kaynamama

c. Tip B3: Kemik defekti ve uzunluk kaybı olan kaynamama

Bu sınıflama diğer kemiklerde görülen kaynamamalarda da kullanılabilir özelliktedir.

\section{KAYNAKLAR}

1. Brett RB, William MR. Principles of nonunion treatment. In: Bucholz RW, Heckman JD, Court-Brown CM, Tornetta $P$, editors. Rockwood and Green's Fractures in Adults, 7th ed. Philadelphia: Lippincott, Williams \& Wilkins; 2010. pp.644-45.

2. Cleveland KB. Delayed union and nonunion of fractures. In: Canale ST, Beaty JH, editors. Campbell's Operative Orthopaedics, 12th ed. Elsevier Mosby; 2012. pp.2982-84.

3. Reisoğlu A, Ağuş H. Kaynamamalarda (Psödoartroz) Tanı ve Tedavi. TOTBID Derg 2008;7(1-2):72-80.

4. Paley D, Catagni MA, Argnani F, Villa A, Benedetti GB, Cattaneo R. Ilizarov treatment of tibial nonunion with bone loss. Clin Orthop Relat Res 1989;(241):146-65. 